(C) А.В. Дедик

\title{
БИЛАТЕРАЛЬНАЯ АСИММЕТРИЯ ДЛИННЫХ КОСТЕЙ СКЕЛЕТА У ТОБОЛО-ИРТЫШСКИХ ТАТАР*
}

В статье представлень результаты изучения билатеральной асимметрии длинных костей скелета у четырёх групп тоболо-иртышских татар: аяльнских, тобольских, тюменских и коурдакско-саргатских татар. Для каждой группы мужчин и женщин была рассчитаны коэффищиенты асимметрии (использовалась формула $R-L)$, прочентное соотномение которых показывает, что наиболее симметричная скелетная система у аяльнских татар, а самая асимметричная у коурдакско-саргатских татар. При анализе коэффициентов асимметрии отдельных костей, было выявлено, что во всех исследуемых группах у мужчин и женщин самой асимметричной костью является плечевая кость. Анализ коэффиџиентов асимметрии по отдельным признакам показал, что во всех группах наибольшей асимметрией отличаются продольнье диаметры костей верхних конечностей. Левосторонняя асимметрия в группах тоболо-иртышских татар в основном характерна для признаков костей нижних конечностей как у мужчин, так и у женщин. Закономерности в половом распределении коэффищиентов асимметрии в группах тоболо-иртылиских татар выявлены не были. Для наглядности изменчивости коэффициентов асимметрии для мужских и женских групп тоболо-иртышиских татар были построень комбинационные полигоны, форма которых показала, что наиболее схожи между собой мужчины тобольских и коурдакско-саргатских татар, а аяльнские и тюменские татары заметно отличаются как от этих групп, так и между собой. Формы комбинационных полигонов женских серий тоболо-иртылиских татар не обнаруживают видимого сходства между собой. Таким образом, выявленные различия в асимметрии скелетной системы этно-территориальных групп тоболо-иртышских татар, возможно, связаны с хозяйственным укладом жизни татар, который, ввиду различной территории расселения тех или иных этно-территориальных групп, заметно отличался.

Ключевые слова: физическая антропология, билатеральная асимметрия, тоболо-иртышские татары

Ссылка при цитировании: Дедик А.В. Билатеральная асимметрия длинных костей скелета у тоболо-иртышских татар // Вестник антропологии, 2021. № 2. С. 292-310.

Дедик Алена Владимировна - специалист Лаборатории археологии Енисейской Сибири, Гуманитарный институт СФУ (г. Красноярск, Свободный просп., 82А). Эл. почта: ejara.ru@mail.ru

* Статья представляет собой расширенную версию доклада, прозвучавшего на V Молодёжной антропологической конференции «Актуальные проблемы физической антропологии: преемственность и новые подходы», 25-28 марта 2019 г. в Москве 


\section{Введение}

Настоящая статья посвящена изучению флуктурирующей и направленной асимметрии по классификации, предложенной Van Valen в 1962 (Van Valen 1962) длинных костей посткраниального скелета тоболо-иртышских татар. Прежде чем перейти к конкретному исследованию, следует остановится на некоторых терминологических моментах. Исходя из классификации (Van Valen 1962), при флуктуирующей асимметрии мы имеем дело с незначительными, ненаправленными отклонениями от строгой билатеральной симметрии. Направленная асимметрия человека проявляет свойства, определяемые генотипом (поэтому используется меньше в целях биоиндикации), но она также связана с функциональной асимметрией человека. При изучении палеопопуляций человека значительное внимание уделяется именно изучению показателей направленной и флуктуирующей асимметрий. Из выделяемых основных видов функциональной асимметрии, моторной, сенсорной и психической (Брагина, Доброхотова 1981: 11) палеоантрополога наиболее интересует моторная. Поскольку направленная асимметрия длинных костей может формироваться в результате функциональной адаптации организма к механическим факторам, также зависимость между направленной асимметрией и механическим стрессом костей конечностей может быть использована при изучении физических нагрузок в палеопопуляциях в связи с их хозяйственным укладом, а также гендерным разделением труда (Тур 2014: 142).

Значения флуктуирующей асимметрии, имеющей незначительные отклонения, могут быть достаточно малы, а если в организме присутствует направленная асимметрия, то оценить (измерить) флуктуирующую асимметрию методически практически невозможно (Palmer 2004). Поэтому проявление флуктуирующей асимметрии в большинстве случаев изучают именно на одонтологических и краниологических останках (Typ 2014). К примеру, показатели флуктуирующей асимметрии на зубах широко используются в качестве индикатора средового воздействия на индивидуумов в популяции (Худавердян 2014: 227). Считается, что чем сильнее негативное (стрессовое) воздействие, тем больше величина флуктуирующей асимметрии как в природных популяциях, так и в контролируемых лабораторных группах особей. Однако стоит отметить, что данная закономерность не всегда подтверждается эмпирическими данными (Зорина 2012: 25).

Асимметрия каких-либо структур организма, отдельных признаков или их комплекса оценивается на определенной стадии развития. Однако в зависимости от возраста или стадии морфогенеза величина и изменчивость многих признаков со временем не остаются постоянными и могут значительно меняться (Зорина 2014: 31).

На сегодняшний день количество публикаций и объем накопленных данных явно недостаточны для полноценного использования критерии асимметрии, как маркера экологических стрессов, особенно на костях посткраниального скелета. Количество публикаций, в которых обсуждаются проблемы асимметрии, несомненно, растет с каждым днем, однако работ, посвященных анализу показателей асимметрии на палеоантропологических останках не так много.

Цель данной работы - выявить и сравнить билатеральную асимметрию длинных костей скелета у тоболо-иртышских татар.

В соответствии с целью поставлены следующие задачи:

- проанализировать отечественные работы и выявить основные тенденции раз- 
вития изучения показателей асимметрии на палеоантропологических останках;

- вычислить показатели асимметрии в четырёх этно-территориальных группах тоболо-иртышских татар;

- сравнить полученные показатели с целью выявления сходства и различий.

В ранних отечественных работах по асимметрии длинных костей исследователи уделяли внимание только продольным размерам костей тех или иных популяций, другие размеры оставались без учета и анализа (см. к примеру: Рождественский 1929; Гинзбург 1947). В 1960 г. вышла работа В.Г. Властовского по асимметрии скелета конечностей человека, в которой автор впервые провел сравнительное исследование остеологической серии русских с сериями скелетов лесной куницы и серебристо-черной лисицы. В анализ вошли как продольные размеры, так и широтные размеры у эпифизов и диафизов (Властовский 1960). В работе автор подтверждает наличие у человека хорошо выраженной правосторонней асимметрии руки и перекрестной - у обеих конечностей: правая рука - левая нога. На основе результатов сравнения скелетов человека и животных автор подчеркивает, что следует различать морфологическую и функциональную асимметрию. Функциональная асимметрия приобретение чисто человеческое, а морфологическая унаследована человеком от животных предков (Властовский 1960: 10-11).

Следующие работы вышли только в 1990-ых гг. по асимметрии лицевого отдела черепа человека (Ан 1993; 1999). К сожалению, данная тема не получила дальнейшего развития среди антропологов, однако тематика асимметрии лицевого скелета человека нашла отражение во многих медицинских работах (см. к примеру: Николаева 2007; Дубовик 2009 и др.).

В начале 2000-ых снова начинает проявляться интерес к билатеральной асимметрии палеопопуляций. В своей работе Д.В. Пежемский наряду с детальной остеологической характеристикой серии ногайцев XVIII - первой половины XIX в. анализирует и коэффициенты асимметрии длинных костей (Пежемский 2003). Помимо особенностей асимметрии, которые присущи данной палеопопуляции, было выявлено определенное сходство ногайцев с выборкой русских, которые, по мнению автора, связаны непосредственно с общебиологическими закономерностями: наибольшая асимметрия плечевых костей, правосторонняя асимметрия верхних конечностей и левосторонняя асимметрия нижних конечностей (Пежемский 2003).

Следующие работы по асимметрии длинных конечностей вышли относительно недавно (Тур 2014; Березина 2017). Авторы в своих работах делают упор на изучение нормальности распределения коэффициентов асимметрии в изучаемых группах, поэтому приведено большое количество различных статистических анализов и их результаты. Однако, к сожалению, Н.Я. Березина не публикует коэффициенты асимметрии, а лишь приводит данные по различным статистическим анализам этих коэффициентов, поэтому серия по раннесредневековому населению Северной Oceтии для сравнительного анализа не может быть использована (Березина 2017). Несомненным плюсом данных работ является вычисление авторами ошибки измерения, которая, на сегодняшний момент, почти не высчитывается и не анализируется не только в остеологических, но и в краниологических работах.

Флуктуирующий характер асимметрии, как уже было сказано выше, зачастую проявляется именно на зубной системе человека, ввиду малых значений измерительных признаков. В отечественной науке работ по изучению асимметрии одонтологических 
серий палеопопуляций совсем немного. Тем не менее было установлено, что флуктуирующая асимметрия зубов человека, наиболее выраженная у древних представителей гоминид, связана с колебаниями пенетрантности и экспрессивности генов в силу целого комплекса причин генетического характера (Зубов, Халдеева 1989: 28). Также имеются работы, в которых исследователи на примерах отдельных общностей пытались выявить связь флуктуирующей асимметрии зубной системы человека с некоторыми показателями физиологического стресса (Худавердян 2014; Бужилова 2017).

По результату обзора работ видим, что тема изучения асимметрии палеопопуляций в отечественной литературе не очень популярна. Данное обстоятельство влечет за собой проблему отсутствия единой методологической базы по изучению асимметрии на скелетных останках человека.

\section{Материалы и методы}

Материалами для исследования послужили остеологические коллекции следующих этно-территориальных групп тоболо-иртышских татар.

Аялынские (тарские) татары. Материалы получены в результате работ на могильнике Чеплярово 27 (XVII-XVIII вв.) в Муромцевском районе Омской области. Памятник был открыт М.А. Корусенко и исследован им в 1999, 2005-2009 гг. (Корусенко 2010).

Данные по коурдакско-саргатским татарам получены с территории могильника Тюльчаково (XIX - начало XX в.) в Усть-Ишимском районе Омской области, изученного в 1983 г. А.Н. Багашёым (Багашёв 1993).

Тобольские татары представлены коллекцией с территории могильника Островной (XIX - начало XX в.), расположенного в Тобольском районе Тюменской области. Памятник открыт, обследован и изучен А.Н. Багашёвым в 1984-1985 гг. (Багашёв 1993).

Материалы по группе тюменских татар получены А.Н. Багашёвым в ходе работ на памятнике Юртобор (XIX - начало XX в.) в Ярковском районе Тюменской области в 1985-1986 гг. (Багашёв 1993).

Индивидуальные остеометрические измерения по тобольским, тюменским и коурдакско-саргатским татарам взяты из кандидатской диссертации А.Н. Багашёва (Багашёв 1989). Также по данным группам автором настоящего исследования дополнительно были измерены 7 остеометрических признаков (Humerus №№ признаков 3, 4, 9, 10; Femur №oo 18, 19; Tibia № 1a), которые по различным причинам не были включены в программу измерения А.Н. Багашёва. Группа аялынских татар представлена неопубликованными данными автора настоящей статьи.

Методы исследования. Изучение изменчивости скелетной системы проведено при помощи вычисления и анализа коэффициентов асимметрии, которые представляют собой среднее арифметическое разности индивидуальных значений по каждому отдельному признаку. На сегодняшний момент в литературе встречаются несколько основных формул для вычисления значения асимметрии:

- $\quad$ R-L - формула, при которой из величины размера правой стороны вычитается соответствующая величина левой стороны (Гинзбург 1947; Властовский 1960; Пежемский 2003);

- $\quad \mathrm{L}-\mathrm{R}$ - разность между измерениями левой и правой сторон признака (Березина 2017); 
- $\quad[(\mathrm{R}-\mathrm{L}) / 0,5 *(\mathrm{R}+\mathrm{L})]^{*} 100$ - разность измерений признака справа и слева, деленная на полусумму тех же измерений, умноженная на 100 (Typ 2014).

При работе автором статьи была использована формула R-L. Стоит отметить, что зачастую выбор формулы зависит от методики, применяемой авторами в тех работах, которые используются в качестве сравнительного материала.

При вычислении коэффициентов асимметрии обязательно учитывался знак, поскольку отрицательные значения коэффициентов характеризуют левостороннюю асимметрию. В качестве значимых рассматривались коэффициенты, величина которых $\geq 0,5$. Из статистических параметров было вычислено и проанализировано стандартное отклонение (сигма) серий. Для проверки достоверности различий между коэффициентами асимметрии в изучаемых и сравниваемых сериях использовался t-критерий Стьюдента, рассчитанный в программе Microsoft Excel 2010. С целью выявления взаимосвязей между коэффициентами асимметрии был проведен корреляционный анализ в программе Statistica 10.0. Для наглядности изменчивости коэффициентов асимметрии были построены полигоны. За основу был введен такой параметр как общая асимметричность класса кости, который равен сумме средних значений коэффициентов асимметрии всех признаков каждой кости (плечевая, лучевая, локтевая, бедренная и большая берцовая кость).

\section{Результаты и их обсуждение}

В таблицах 1-4 представлены коэффициенты асимметрии длинных костей скелета всех мужских и женских групп тоболо-иртышских татар.

Таблица 1

Коэффициенты асимметрии длинных костей скелета аялынских татар (могильник Чеплярово 27)

\begin{tabular}{|c|c|c|c|c|c|c|}
\hline \multirow{2}{*}{$\begin{array}{l}\text { Признак по Мартину } \\
\text { Плечевая кость }\end{array}$} & \multicolumn{6}{|c|}{ Коэффициенты асимметрии } \\
\hline & $\mathbf{n}$ & $\sigma$ & мужчины & $\mathbf{n}$ & $\sigma$ & женщины \\
\hline 1. Наибольшая длина & 22 & 3,0 & 1,82 & 10 & 2,7 & 1,20 \\
\hline 2. Вся длина & 22 & 3,1 & 0,82 & 10 & 2,6 & 0,30 \\
\hline 3. Верх. эпифиз. ширина & 22 & 1,8 & 0,05 & 10 & 1,5 & 0,80 \\
\hline 4. Ниж. эпифиз. ширина & 20 & 2,2 & $-0,50$ & 12 & 2,5 & $-0,58$ \\
\hline 5. Наиб. Ø сер. диафиза & 24 & 0,8 & 0,03 & 14 & 1,1 & $-0,02$ \\
\hline 6. Наим. Ø сер. диафиза & 24 & 0,5 & $-0,07$ & 14 & 0,6 & 0,24 \\
\hline 7. Наим. окруж. диафиза & 24 & 1,1 & $-0,08$ & 15 & 1,9 & 0,13 \\
\hline 9. Наиб. ширина головки & 16 & 1,2 & 0,00 & 6 & 0,6 & 0,00 \\
\hline 10. Верт. диаметр головки & 20 & 1,0 & $-0,19$ & 7 & 0,4 & 0,83 \\
\hline \multicolumn{7}{|l|}{ Лучевая кость } \\
\hline 1. Наибольшая длина & 18 & 3,2 & 0,11 & 11 & 2,8 & $-0,36$ \\
\hline 2. Физиологич. длина & 22 & 2,5 & 0,32 & 13 & 3,3 & 0,08 \\
\hline 4. Попер. Ø диафиза & 23 & 1,1 & $-0,01$ & 13 & 1,4 & 0,75 \\
\hline
\end{tabular}


Таблица 1 (продолжить)

\begin{tabular}{|c|c|c|c|c|c|c|}
\hline \multirow{2}{*}{$\begin{array}{l}\text { Признак по Мартину } \\
\text { Плечевая кость }\end{array}$} & \multicolumn{6}{|c|}{ Коэффициенты асимметрии } \\
\hline & $\mathbf{n}$ & $\boldsymbol{\sigma}$ & мужчины & $\mathbf{n}$ & $\sigma$ & женщины \\
\hline 5. Сагитт. Ø диафиза & 23 & 0,5 & $-0,13$ & 13 & 0,5 & 0,20 \\
\hline 3. Наим. окружн. диафиза & 23 & 1,4 & 0,65 & 15 & 1,6 & 0,67 \\
\hline \multicolumn{7}{|l|}{ Локтевая кость } \\
\hline 1. Наибольшая длина & 10 & 3,1 & 0,00 & 2 & - & 1,50 \\
\hline 2. Физиологич. длина & 16 & 3,8 & 1,69 & 6 & 4,0 & 0,33 \\
\hline 11. Сагитт. Ø диафиза & 24 & 1,3 & $-0,30$ & 11 & 0,8 & 0,39 \\
\hline 12. Попер. Ø диафиза & 23 & 1,4 & $-0,21$ & 11 & 0,6 & 0,55 \\
\hline 13. Верх. попер. Ø & 24 & 1,4 & $-0,49$ & 12 & 0,9 & $-0,05$ \\
\hline 14. Верх. сагитт. Ø & 24 & 1,8 & $-0,20$ & 13 & 1,1 & $-0,34$ \\
\hline 3. Наим. окружн. диафиза & 23 & 1,4 & $-0,17$ & 12 & 1,8 & 1,00 \\
\hline
\end{tabular}

Ключица

\begin{tabular}{l|c|c|c|c|c|c} 
1. Наибольшая длина & 14 & 2,6 & $-2,07$ & 4 & - & $-0,50$ \\
6. Окружн. сер. диафиза & 24 & 1,4 & 0,79 & 14 & 1,4 & $-0,36$
\end{tabular}

Бедренная кость

\begin{tabular}{|c|c|c|c|c|c|c|}
\hline 1. Наибольшая длина & 24 & 3,1 & $-0,08$ & 17 & 2,7 & $-0,94$ \\
\hline 2. Длина в ест. положении & 23 & 4,0 & $-1,22$ & 17 & 2,4 & $-0,88$ \\
\hline 21. Мыщелковая ширина & 15 & 1,1 & 0,00 & 4 & - & 0,75 \\
\hline 6. Сагитт. Ø сер. диафиза & 24 & 1,2 & 0,28 & 17 & 1,6 & $-0,23$ \\
\hline 7. Попер. Ø сер. диафиза & 24 & 0,8 & $-0,10$ & 17 & 1,6 & $-0,28$ \\
\hline 9. Верх. попер. Ø диафиза & 24 & 1,3 & $-0,34$ & 16 & 1,1 & $-0,08$ \\
\hline 10. Верх. сагитт. Ø диафиза & 24 & 1,5 & $-0,57$ & 15 & 0,8 & $-0,12$ \\
\hline 8. Окружн. сер. диафиза & 24 & 1,4 & $-0,04$ & 16 & 1,3 & 0,31 \\
\hline 18. Верт. диаметр головки & 24 & 0,6 & $-0,02$ & 14 & 0,5 & 0,43 \\
\hline 19. Ширина головки & 23 & 0,9 & 0,15 & 13 & 0,8 & 0,42 \\
\hline \multicolumn{7}{|l|}{ Большая берцовая кость } \\
\hline 1. Общая длина & 21 & 2,7 & 0,38 & 13 & 3,4 & $-0,23$ \\
\hline 1а. Наибольшая длина & 22 & 2,7 & 0,05 & 13 & 3,6 & 0,23 \\
\hline 8а. Верх. сагитт. Ø & 24 & 1,5 & $-0,61$ & 17 & 1,5 & $-0,05$ \\
\hline 9а. Верх. попер. Ø & 24 & 0,9 & $-0,10$ & 17 & 0,9 & $-0,01$ \\
\hline 10b. Окружн. сер. диафиза & 23 & 1,0 & 0,04 & 17 & 0,9 & 0,29 \\
\hline \multicolumn{7}{|l|}{ Малая берцовая кость } \\
\hline 1. Наибольшая длина & 13 & 3,1 & $-0,08$ & 6 & 2,9 & $-0,33$ \\
\hline 4а. Наим. окружность & 18 & 1,6 & 0,33 & 13 & 0,5 & 0,06 \\
\hline
\end{tabular}

* Примечание: жирным шрифтом выделены повышенные коэффициенты асимметрии, величина которых $\geq 0,5$. 
На сегодняшний момент ввиду отсутствия систематического изучения билатеральной асимметрии в палеопопуляциях, каких-либо математических методов, позволяющих оценить размах изменчивости коэффициентов асимметрии не существует. Поскольку коэффициенты асимметрии обладают большой индивидуальной изменчивостью, то вычисление и анализ коэффициентов вариации не будут адекватно отражать характер изменчивости. Стандартное отклонение (сигма) может быть посчитано, однако ввиду отсутствия данных по асимметрии разных серий размах сигмы нам неизвестен. Поэтому в сложившейся ситуации можно анализировать сигмы между исследуемыми группами.

По итогам анализа стандартных отклонений было установлено, что величины сигмы во всех группах тоболо-иртышских татар разделились на две группы: в первую попадают более повышенные коэффициенты асимметрии продольных размеров, а во вторую - менее повышенные коэффициенты поперечных размеров (см. таблица 1-4). Анализ также выявил, что женщины тюменских татар имеют самые высокие сигмы по сравнению с другими женскими группами тоболо-иртышских татар. Каких-либо других отличий по результатам анализа стандартных отклонений между изучаемыми группами обнаружено не было.

Таблица 2

Коэффициенты асимметрии в серии тюменских татар (могильник Юртобор 4а)

\begin{tabular}{|c|c|c|c|c|c|c|}
\hline \multirow{2}{*}{$\begin{array}{l}\text { Признак по Мартину } \\
\text { Плечевая кость }\end{array}$} & \multicolumn{6}{|c|}{ Коэффициенты асимметрии } \\
\hline & $\mathbf{n}$ & $\sigma$ & мужчины & $\mathbf{n}$ & $\sigma$ & женщинь \\
\hline 1. Наибольшая длина & 33 & 4,4 & $3, \mathbf{8 8}$ & 15 & 4,2 & 2,47 \\
\hline 2. Вся длина & 32 & 3,6 & 3,41 & 15 & 3,6 & 2,73 \\
\hline 3. Верх. эпифиз. ширина & 16 & 2,1 & 0,69 & 8 & 1,7 & 0,13 \\
\hline 4. Ниж. эпифиз. ширина & 21 & 2,4 & 0,43 & 7 & 3,7 & 0,14 \\
\hline 5. Наиб. Ø сер. диафиза & 33 & 1,0 & 0,39 & 15 & 0,9 & 0,20 \\
\hline 6. Наим. Ø сер. диафиза & 33 & 0,9 & 0,24 & 15 & 0,7 & 0,00 \\
\hline 7. Наим. окруж. диафиза & 31 & 2,0 & 0,61 & 15 & 2,0 & 0,00 \\
\hline 9. Наиб. ширина головки & 14 & 1,6 & 0,93 & 6 & 1,5 & $-0,33$ \\
\hline 10. Верт. диаметр головки & 15 & 1,3 & 0,40 & 6 & 1,0 & 0,17 \\
\hline \multicolumn{7}{|l|}{ Лучевая кость } \\
\hline 1. Наибольшая длина & 26 & 3,1 & 4,04 & 12 & 4,3 & 3,58 \\
\hline 2. Физиологич. длина & 26 & 3,1 & 2,27 & 12 & 2,8 & 1,58 \\
\hline 4. Попер. Ø диафиза & 25 & 1,5 & $\mathbf{0 , 8 8}$ & 10 & 1,7 & 0,40 \\
\hline 5. Сагитт. Ø диафиза & 25 & 1,4 & 0,28 & 10 & 0,9 & 0,20 \\
\hline 3. Наим. окружн. диафиза & 27 & 2,7 & 0,63 & 11 & 2,7 & 0,36 \\
\hline \multicolumn{7}{|l|}{ Локтевая кость } \\
\hline 1. Наибольшая длина & 15 & 3,9 & 1,93 & 8 & 4,3 & 0,25 \\
\hline 2. Физиологич. длина & 16 & 2,4 & 1,75 & 8 & 3,5 & 0,50 \\
\hline
\end{tabular}


Таблица 2 (продолжение)

\begin{tabular}{l|c|c|c|c|c|c}
\hline Признак по Мартину & \multicolumn{7}{|c}{ Коэффициенты асимметрии } \\
\hline Плечевая кость & $\mathbf{n}$ & $\boldsymbol{\sigma}$ & мужчины & $\mathbf{n}$ & $\boldsymbol{\sigma}$ & женщины \\
\hline 11. Сагитт. Ø диафиза & 27 & 1,6 & 0,07 & 9 & 0,9 & $-0,11$ \\
12. Попер. Ø диафиза & 27 & 1,7 & 0,22 & 9 & 1,8 & $-0,11$ \\
13. Верх. попер. Ø & 28 & 1,0 & $-0,04$ & 12 & 1,7 & $\mathbf{- 0 , 5 8}$ \\
\hline 14. Верх. сагитт. Ø & 28 & 1,7 & 0,11 & 12 & 0,8 & 0,08 \\
\hline 3. Наим. окружн. диафиза & 23 & 1,4 & $\mathbf{0 , 7 8}$ & 9 & 1,8 & $\mathbf{- 1 , 0 0}$
\end{tabular}

\section{Ключица}

1. Наибольшая длина

6. Окружн. сер. диафиза

\begin{tabular}{l|l}
26 & 3,0 \\
29 & 2,1 \\
\hline
\end{tabular}

$\mathbf{0 , 8 8}$
$-0,03$

\begin{tabular}{|c|c|c}
12 & 2,2 & 0,33 \\
\hline 14 & 1,9 & $\mathbf{- 0 , 6 4}$
\end{tabular}

Бедренная кость

\begin{tabular}{|c|c|c|c|c|c|c|}
\hline 1. Наибольшая длина & 33 & 3,7 & 0,30 & 16 & 4,5 & $-0,25$ \\
\hline 2. Длина в ест. положении & 33 & 3,7 & $-0,03$ & 16 & 3,8 & $-0,63$ \\
\hline 21. Мыщелковая ширина & 32 & 2,1 & $-0,22$ & 15 & 2,5 & $\mathbf{0 , 8 0}$ \\
\hline 6. Сагитт. Ø сер. диафиза & 33 & 1,3 & 0,30 & 16 & 1,2 & 0,06 \\
\hline 7. Попер. Ø сер. диафиза & 33 & 1,8 & 0,12 & 16 & 1,5 & $-0,31$ \\
\hline 9. Верх. попер. Ø диафиза & 33 & 1,2 & $-0,09$ & 16 & 2,0 & 0,00 \\
\hline 10. Верх. сагитт. Ø диафиза & 33 & 0,9 & $-0,30$ & 16 & 1,0 & 0,00 \\
\hline 8. Окружн. сер. диафиза & 33 & 4,0 & $\mathbf{0 , 7 9}$ & 16 & 2,8 & $-0,31$ \\
\hline 18. Верт. диаметр головки & 22 & 0,9 & 0,32 & 11 & 0,9 & 0,45 \\
\hline 19. Ширина головки & 19 & 1,0 & 1,16 & 8 & 1,2 & 0,38 \\
\hline
\end{tabular}

Большая берцовая кость

\begin{tabular}{|c|c|c|c|c|c|c|}
\hline 1. Общая длина & 32 & 3,1 & $-1,03$ & 16 & 3,0 & $-0,19$ \\
\hline 1а. Наибольшая длина & 25 & 3,0 & 0,32 & 12 & 1,1 & 1,75 \\
\hline 8а. Верх. сагитт. Ø & 30 & 1,3 & $-0,13$ & 16 & 1,3 & $\mathbf{0 , 5 0}$ \\
\hline 9а. Верх. попер. Ø & 30 & 1,0 & 0,17 & 16 & 0,9 & 0,25 \\
\hline 10b. Окружн. сер. диафиза & 30 & 3,3 & $-0,17$ & 15 & 2,5 & 1,00 \\
\hline \multicolumn{7}{|l|}{ Малая берцовая кость } \\
\hline 1. Наибольшая длина & 15 & 3,8 & 1,13 & 9 & 2,5 & 1,11 \\
\hline 4а. Наим. окружность & 22 & 1,8 & 0,18 & 10 & 0,9 & $\mathbf{0 , 8 0}$ \\
\hline
\end{tabular}

Процентные соотношения коэффициентов асимметрии показывают, что группой с наиболее симметричной скелетной системой являются аялынские татары, у которых в $75 \%$ случаев у мужчин и в $70 \%$ случаев у женщин отсутствует заметная асимметрия (см. таблица 1). Тобольские татары демонстрируют также небольшие показатели асимметрии (всего $30 \%$ у мужчин и $35 \%$ у женщин) (таблица 3 ). 
Таблица 3

Коэффициенты асимметрии в серии тобольских татар (могильник Островной)

\begin{tabular}{|c|c|c|c|c|c|c|}
\hline \multirow{2}{*}{$\begin{array}{l}\text { Признак по Мартину } \\
\text { Плечевая кость }\end{array}$} & \multicolumn{6}{|c|}{ Коэффициенты асимметрии } \\
\hline & $\mathbf{n}$ & $\sigma$ & мужчины & $\mathbf{n}$ & $\sigma$ & женщины \\
\hline 1. Наибольшая длина & 19 & 3,7 & 2,37 & 12 & 2,1 & 1,83 \\
\hline 2. Вся длина & 19 & 3,9 & 1,26 & 12 & 2,9 & 1,25 \\
\hline 3. Верх. эпифиз. ширина & 14 & 1,2 & 0,29 & 7 & 0,8 & 0,00 \\
\hline 4. Ниж. эпифиз. ширина & 13 & 1,5 & $\mathbf{0 , 5 4}$ & 11 & 1,8 & $-0,09$ \\
\hline 5. Наиб. Ø сер. диафиза & 19 & 0,8 & 0,11 & 12 & 0,8 & 0,58 \\
\hline 6. Наим. Ø сер. диафиза & 19 & 0,7 & 0,21 & 12 & 0,7 & $\mathbf{0 , 5 0}$ \\
\hline 7. Наим. окруж. диафиза & 19 & 1,6 & $\mathbf{0 , 5 8}$ & 12 & 1,0 & $\mathbf{0 , 8 3}$ \\
\hline 9. Наиб. ширина головки & 11 & 0,8 & 0,27 & 2 & - & $\mathbf{0 , 5 0}$ \\
\hline 10. Верт. диаметр головки & 13 & 1,2 & 0,46 & 8 & 0,7 & 0,25 \\
\hline
\end{tabular}

\section{Лучевая кость}

1. Наибольшая длина

2. Физиологич. длина

4. Попер. Ø диафиза

5. Сагитт. Ø диафиза

3. Наим. окружн. диафиза

\begin{tabular}{c|c|c|c|c|c}
19 & 1,9 & $\mathbf{1 , 3 2}$ & 12 & 2,6 & $\mathbf{1 , 0 8}$ \\
19 & 2,1 & $\mathbf{0 , 8 9}$ & 12 & 1,6 & $\mathbf{1 , 0 0}$ \\
19 & 1,1 & $-0,05$ & 13 & 0,8 & 0,03 \\
19 & 0,7 & 0,21 & 13 & 0,4 & $-0,25$ \\
19 & 1,4 & 0,26 & 13 & 1,2 & 0,00
\end{tabular}

\section{Локтевая кость}

1. Наибольшая длина

2. Физиологич. длина

11. Сагитт. Ø диафиза

12. Попер. Ø диафиза

13. Верх. попер. Ø

14. Верх. сагитт. Ø

3. Наим. окружн. диафиза

\begin{tabular}{c|c|c|c|c|c}
18 & 2,9 & $\mathbf{1 , 8 3}$ & 9 & 2,5 & $\mathbf{1 , 5 6}$ \\
18 & 2,8 & $\mathbf{1 , 0 6}$ & 9 & 5,1 & 0,11 \\
18 & 1,1 & 0,44 & 12 & 0,5 & 0,25 \\
18 & 1,3 & 0,06 & 12 & 1,0 & $-0,34$ \\
18 & 1,5 & 0,33 & 12 & 1,4 & 0,26 \\
18 & 1,2 & 0,22 & 12 & 1,5 & 0,05 \\
18 & 1,1 & $-0,39$ & 11 & 1,0 & 0,27
\end{tabular}

\section{Ключица}

1. Наибольшая длина

6. Окружн. сер. диафиза

\begin{tabular}{c|c|c|c|c|c}
16 & 3,7 & $\mathbf{- 1 , 3 8}$ & 9 & 3,7 & $-0,22$ \\
\hdashline 17 & 1,3 & 0,00 & 9 & 2,6 & $\mathbf{0 , 5 6}$
\end{tabular}

\section{Бедренная кость}

1. Наибольшая длина

2. Длина в ест. положении

\begin{tabular}{l|l|l|l|l|l}
20 & 3,7 & $\mathbf{- 0 , 7 5}$ & 12 & 2,4 & $-0,33$ \\
20 & 3,3 & $\mathbf{- 0 , 6 5}$ & 12 & 4,1 & $\mathbf{- 1 , 0 8}$
\end{tabular}


Таблица 3 (продолжение)

\begin{tabular}{|c|c|c|c|c|c|c|}
\hline \multirow[t]{2}{*}{ Признак по Мартину } & \multicolumn{6}{|c|}{ Коэффициенты асимметрии } \\
\hline & $\mathbf{n}$ & $\sigma$ & мужчины & $\mathbf{n}$ & $\sigma$ & женщины \\
\hline 21. Мыщелковая ширина & 20 & 1,5 & $-0,05$ & 12 & 1,1 & 0,08 \\
\hline 6. Сагитт. Ø сер. диафиза & 20 & 1,1 & $-0,35$ & 12 & 0,8 & $-0,29$ \\
\hline 7. Попер. Ø сер. диафиза & 20 & 1,0 & 0,05 & 12 & 0,6 & 0,03 \\
\hline 9. Верх. попер. Ø диафиза & 20 & 1,2 & $-0,25$ & 12 & 1,3 & 0,17 \\
\hline 10. Верх. сагитт. Ø диафиза & 20 & 0,8 & $-0,40$ & 12 & 1,1 & $-0,14$ \\
\hline 8. Окружн. сер. диафиза & 20 & 2,0 & $-0,15$ & 12 & 1,6 & 0,00 \\
\hline 18. Верт. диаметр головки & 14 & 0,8 & 0,00 & 12 & 0,9 & $-0,17$ \\
\hline 19. Ширина головки & 14 & 0,8 & 0,43 & 12 & 0,7 & 0,33 \\
\hline \multicolumn{7}{|l|}{ Большая берцовая кость } \\
\hline 1. Общая длина & 19 & 2,6 & $-0,79$ & 13 & 2,4 & $-0,23$ \\
\hline 1а. Наибольшая длина & 16 & 2,2 & 0,38 & 12 & 2,2 & $-0,42$ \\
\hline 8а. Верх. сагитт. Ø & 19 & 1,1 & $-0,11$ & 13 & 0,8 & $-0,96$ \\
\hline 9а. Верх. попер. Ø & 19 & 1,3 & 0,21 & 13 & 1,1 & 0,45 \\
\hline 10b. Окружн. сер. диафиза & 19 & 1,4 & $-0,37$ & 13 & 1,1 & $-0,77$ \\
\hline \multicolumn{7}{|l|}{ Малая берцовая кость } \\
\hline 1. Наибольшая длина & 14 & 2,5 & $-0,14$ & 10 & 2,7 & 1,20 \\
\hline 4а. Наим. окружность & 17 & 1,6 & 0,24 & 13 & 1,1 & $-0,46$ \\
\hline
\end{tabular}

Наибольший процент значимых коэффициентов асимметрии наблюдается у коурдакско-саргатских татар. В этой группе лишь в 52,5\% случаев у мужчин и в 55\% случаев у женщин отсутствует заметная асимметрия (таблица 4). Также достаточно высокий процент коэффициентов асимметрии в группе тюменских татар (42,5\% у мужчин и $37,5 \%$ у женщин) (см. таблица 2).

Таблица 4

Коэффициенты асимметрии в серии коурдакско-саргатских татар (могильник Тюльчаково)

\begin{tabular}{l|c|c|c|c|c|c}
\hline Признак по Мартину & \multicolumn{7}{|c}{ Коэффициенты асимметрии } \\
\hline Плечевая кость & $\mathbf{n}$ & $\boldsymbol{\sigma}$ & мужчины & $\mathbf{n}$ & $\boldsymbol{\sigma}$ & женщины \\
\hline 1. Наибольшая длина & 27 & 4,0 & 1,96 & 9 & 3,7 & 3,33 \\
\hline 2. Вся длина & 27 & 4,4 & 2,04 & 9 & 3,2 & 3,56 \\
3. Верх. эпифиз. ширина & 23 & 1,4 & 0,96 & 8 & 0,9 & 0,50 \\
\hline
\end{tabular}


Таблица 4 (продолжение)

\begin{tabular}{l|c|c|c|c|c|c}
\hline Признак по Мартину & \multicolumn{7}{|c}{ Коэффициенты асимметрии } \\
\hline & $\mathbf{n}$ & $\boldsymbol{\sigma}$ & мужчины & n & б & женщины \\
\hline 4. Ниж. эпифиз. ширина & 24 & 1,8 & $-0,17$ & 9 & 1,5 & 0,67 \\
\hline 5. Наиб. Ø сер. диафиза & 27 & 0,8 & 0,78 & 9 & 0,7 & 0,00 \\
6. Наим. Ø сер. диафиза & 27 & 0,7 & 0,11 & 9 & 1,0 & 0,33 \\
7. Наим. окруж. диафиза & 27 & 2,4 & 0,67 & 9 & 1,1 & 0,67 \\
9. Наиб. ширина головки & 23 & 1,7 & 0,65 & 7 & 1,1 & 0,14 \\
10. Верт. диаметр головки & 23 & 1,3 & 1,00 & 8 & 1,0 & 0,25
\end{tabular}

\section{Лучевая кость}

\begin{tabular}{l|c|c|c|c|c|c} 
1. Наибольшая длина & 23 & 2,3 & 2,26 & 8 & 1,9 & 2,50 \\
2. Физиологич. длина & 23 & 2,9 & 1,65 & 8 & 2,1 & 2,38 \\
4. Попер. Ø диафиза & 23 & 0,9 & 0,48 & 9 & 0,4 & 0,22 \\
5. Сагитт. Ø диафиза & 23 & 0,8 & 0,30 & 9 & 0,4 & $-0,22$ \\
3. Наим. окружн. диафиза & 23 & 1,6 & 0,83 & 9 & 1,2 & 0,89
\end{tabular}

\section{Локтевая кость}

\begin{tabular}{|c|c|c|c|c|c|c|}
\hline 1. Наибольшая длина & 24 & 2,5 & 2,46 & 9 & 2,3 & 2,22 \\
\hline 2. Физиологич. длина & 24 & 2,6 & 1,71 & 9 & 2,7 & 1,56 \\
\hline 11. Сагитт. Ø диафиза & 24 & 2,2 & 0,17 & 9 & 0,8 & 0,33 \\
\hline 12. Попер. Ø диафиза & 24 & 1,2 & 0,00 & 9 & 0,6 & 0,11 \\
\hline 13. Верх. попер. Ø & 24 & 1,8 & 0,46 & 9 & 1,1 & 0,11 \\
\hline 14. Верх. сагитт. Ø & 24 & 1,9 & 0,42 & 9 & 0,7 & 0,00 \\
\hline 3. Наим. окружн. диафиза & 24 & 1,3 & 0,38 & 9 & 1,2 & 0,22 \\
\hline
\end{tabular}

\section{Ключица}

\begin{tabular}{l|l|l|l|l|l|l} 
1. Наибольшая длина & 15 & 6,6 & $-3,80$ & 7 & 2,4 & 0,71 \\
6. Окружн. сер. диафиза & 16 & 1,8 & $-0,25$ & 7 & 2,1 & 1,14 \\
Бедренная кость & & & & & \\
1. Наибольшая длина & 29 & 4,1 & $-0,03$ & 10 & 3,4 & $-0,90$ \\
2. Длина в ест. положении & 29 & 4,0 & $-0,10$ & 10 & 2,6 & $-1,00$ \\
21. Мыщелковая ширина & 28 & 1,0 & 0,39 & 10 & 0,8 & 0,00 \\
6. Сагитт. Ø сер. диафиза & 29 & 1,0 & $-0,28$ & 10 & 0,7 & 0,10 \\
7. Попер. Ø сер. диафиза & 29 & 1,0 & 0,38 & 10 & 0,8 & $-0,30$ \\
9. Верх. попер. Ø диафиза & 29 & 1,4 & $-0,10$ & 10 & 0,9 & 0,30
\end{tabular}


Таблица 4 (продолжение)

\begin{tabular}{l|c|c|c|c|c|c}
\hline Признак по Мартину & \multicolumn{7}{|c}{ Коэффициенты асимметрии } \\
\hline & $\mathbf{n}$ & $\boldsymbol{\sigma}$ & мужчины & $\mathbf{n}$ & $\boldsymbol{\sigma}$ & женщины \\
\hline 10. Верх. сагитт. Ø диафиза & 29 & 1,3 & $-0,79$ & 10 & 1,2 & $-0,30$ \\
\hdashline 8. Окружн. сер. диафиза & 29 & 1,4 & $-0,38$ & 10 & 1,3 & $-0,70$ \\
18. Верт. диаметр головки & 23 & 0,7 & 0,04 & 9 & 0,5 & $-0,44$ \\
\hline 19. Ширина головки & 25 & 0,8 & 0,08 & 10 & 0,3 & $-0,10$
\end{tabular}

\section{Большая берцовая кость}

1. Общая длина
1а. Наибольшая длина
8а. Верх. сагитт. Ø
9а. Верх. попер. Ø
10b. Окружн. сер. диафиза

\begin{tabular}{|c|c|c|c|c}
\hline 28 & 4,0 & $-0,64$ & 10 \\
\hline 24 & 3,6 & $-1,04$ & 10 & \\
\hdashline 27 & 1,2 & $-0,19$ & 10 \\
\hline 27 & 1,5 & 0,74 & 10 \\
\hdashline 28 & 1,7 & 0,36 & 10 \\
\hdashline
\end{tabular}

\begin{tabular}{|c|c}
2,5 & $-0,60$ \\
2,1 & $-0,20$ \\
1,4 & $-0,20$ \\
\hline 1,2 & 1,10 \\
2,4 & 1,00
\end{tabular}

\section{Малая берцовая кость}

\begin{tabular}{l|c|c|c|c|c|c} 
1. Наибольшая длина & 20 & 3,6 & 0,80 & 7 & 3,0 & 0,14 \\
4а. Наим. окружность & 25 & 2,1 & 0,68 & 8 & 1,5 & 0,38 \\
\hline
\end{tabular}

Закономерности в половом распределении коэффициентов асимметрии в группах тоболо-иртышских татар выявлены не были. В группах тобольских и аялынских татар женщины являются наиболее асимметричными, а тюменские и коурдакско-саргатские татары, наоборот, имеют более асимметричных мужчин. Необходимо отметить, что различия между коэффициентами асимметрии мужских и женских серий небольшие и составляют не более $5 \%$ в каждой группе.

Закономерности в половом распределении коэффициентов асимметрии в группах тоболо-иртышских татар выявлены не были. В группах тобольских и аялынских татар женщины являются наиболее асимметричными, а тюменские и коурдакско-саргатские татары, наоборот, имеют более асимметричных мужчин. Необходимо отметить, что различия между коэффициентами асимметрии мужских и женских серий небольшие и составляют не более $5 \%$ в каждой группе.

При анализе коэффициентов асимметрии отдельных костей, было выявлено, что во всех исследуемых группах у мужчин самой асимметричной костью является плечевая кость, в женских сериях также плечевая кость имеет наиболее высокие показатели коэффициентов асимметрии по всем признакам. Исключение составляют только женщины тюменских татар, у которых большая берцовая кость является наиболее асимметричной костью.

Анализ коэффициентов асимметрии по отдельным признакам показал, что во всех группах наибольшей асимметрией отличаются продольные диаметры костей верхних конечностей. Полученные результаты хорошо согласуются с данными как по русским группам (Властовский 1960), так и по ногайцам (Пежемский 2003). Однако наши результаты противоположны данным, полученным по скотоводам Алтая 
эпохи бронзы и раннего железного века, которые характеризуются повышенной асимметрией поперечных размеров диафизов (Тур 2014).

Левосторонняя асимметрия в группах тоболо-иртышских татар в основном характерна для признаков костей нижних конечностей как у мужчин, так и у женщин (см. таблицу 1-4). Однако им присуща и небольшая левосторонняя асимметрия верхних конечностей. В частности, мужская и женская часть населения аялынских татар демонстрирует повышенные коэффициенты левосторонней асимметрии нижней эпифизарной ширины плечевой кости (Humerus. 4) (см. таблицу 1). Также повышенные показатели левосторонней асимметрии наибольшей длины ключицы (Cl.1), что в целом является нормой, характерны для мужчин аялынских, тобольских и коурдакско-саргатских татар. Однако мужчины из тюменской группы снова показывают определенное своеобразие, демонстрируя небольшую правостороннюю асимметрию длины ключицы.

При анализе асимметрии одной из дополнительных задач являлась проверка допустимости объединения мужских и женских серий в исследуемых группах в одну общую выборку. К примеру, в работе В.Г. Властовского ввиду малочисленности женских костяков в серии они были объединены вместе с мужской (Властовский 1960). Однако возможность объединения выборок никак не было доказано статистически.

Проведенный анализ t-критерий Стьюдента значимых коэффициентов асимметрии $(\geq 0,5)$ по всем выборкам тоболо-иртышских татар показал, что коэффициенты асимметрии мужской и женской серии не обнаруживают значимых различий, а значит, при определенных задачах исследования данные группы могут быть объединены в одну общую выборку.

Как уже было сказано выше, методологической базы по изучению коэффициентов асимметрии на сегодняшний момент не существует, а, следовательно, отсутствуют общепринятые методы визуализации полученных результатов. Поэтому для наглядности изменчивости коэффициентов асимметрии для мужских и женских групп тоболо-иртышских татар были выбраны и построены комбинационные полигоны, за основу которых был взят такой параметр, как общая асимметричность класса кости (таблица 5-6).

Таблица 5

Значения общей асимметричности каждого класса костей (мужчины)

\begin{tabular}{|c|c|c|c|c|c|}
\hline $\begin{array}{r}\text { Класс кости } \\
\text { Группа татар }\end{array}$ & Плечевая & Лучевая & Локтевая & Бедренная & $\begin{array}{l}\text { Большая } \\
\text { берцовая }\end{array}$ \\
\hline Аялынские & 1,87 & 0,93 & 0,32 & $-1,94$ & $-0,24$ \\
\hline Тюменские & 10,98 & 8,10 & 4,83 & 2,35 & $-0,84$ \\
\hline Тобольские & 6,08 & 2,63 & 3,56 & $-2,12$ & $-0,68$ \\
\hline Коурдакско-саргатские & 8,00 & 5,52 & 5,58 & $-1,55$ & $-0,77$ \\
\hline
\end{tabular}

Результаты эмпирического анализа, а также формы полученных полигонов показывают, что наиболее схожи между собой мужчины тобольских и коурдакско-саргатских татар. Мужские группы аялынских и тюменских татар заметно отличаются. Причем различия видны как между собой, так и по сравнению с тобольскими и коурдакско-саргатскими татарами (рис. 1). 
Таблица 6

Значения общей асимметричности класса костей (женщины)

\begin{tabular}{|c|c|c|c|c|c|}
\hline $\begin{array}{l}\text { Класс кости } \\
\text { Группа татар }\end{array}$ & Плечевая & Лучевая & Локтевая & $\begin{array}{c}\text { Бедрен- } \\
\text { ная }\end{array}$ & $\begin{array}{l}\text { Большая } \\
\text { берцовая }\end{array}$ \\
\hline Аялынские & 2,90 & 1,33 & 3,39 & $-0,61$ & 0,24 \\
\hline Тюменские & 5,50 & 6,13 & $-0,97$ & 0,19 & 3,31 \\
\hline Тобольские & 5,66 & 1,87 & 2,16 & $-1,40$ & $-1,93$ \\
\hline Коурдакско-саргатские & 9,45 & 5,76 & 4,56 & $-3,34$ & 1,10 \\
\hline
\end{tabular}

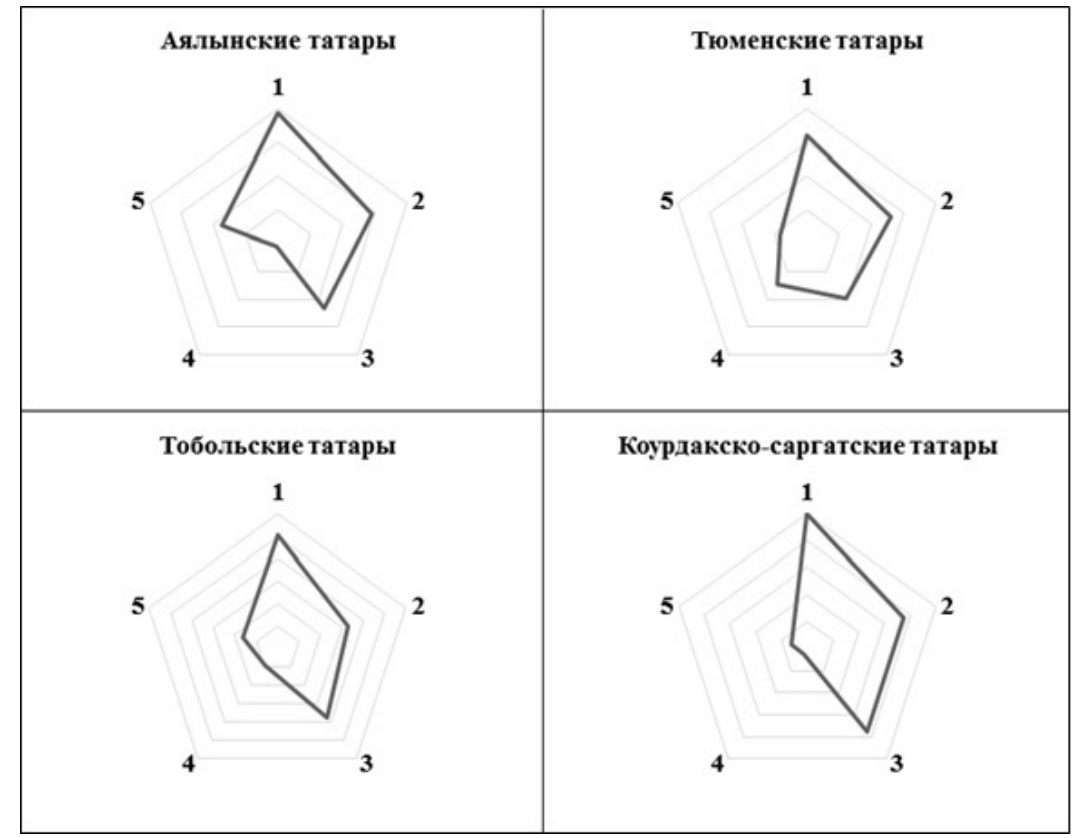

Рис. 1. Комбинационные полигоны общей асимметричности класса кости (мужчины):

1 - плечевая кость; 2 -лучевая кость; 3 -локтевая кость; 4 -бедренная кость; 5 - большая беризовая кость.

Для изучения взаимосвязи между коэффициентами асимметрии был проведен корреляционный анализ по всем остеометрическим признакам. Необходимо отметить, что определённая схожесть тобольской и коурдакско-саргатской группы татар позволила объединить полученные показатели в общую выборку (76 индивидов). По итогам анализа значимые коэффициенты корреляции $(\geq 0,5)$ выявлены не были. Однако во всех группах некоторые продольные признаки костей (наибольшая длина, физиологическая длина) демонстрируют достаточно высокие коэффициенты корреляции (0.8), что, скорее всего, связано с одинаковой природой происхождения данных признаков.

Формы комбинационных полигонов женских серий тоболо-иртышских татар не обнаруживают видимого сходства между собой (рис. 2).

Сравнение формы полигонов у мужчин и женщин показывает, что наиболее схожими между собой по коэффициентам асимметрии являются коурдакско-саргатские татары, в остальных сериях формы полигонов мужской и женской части населения различаются. 


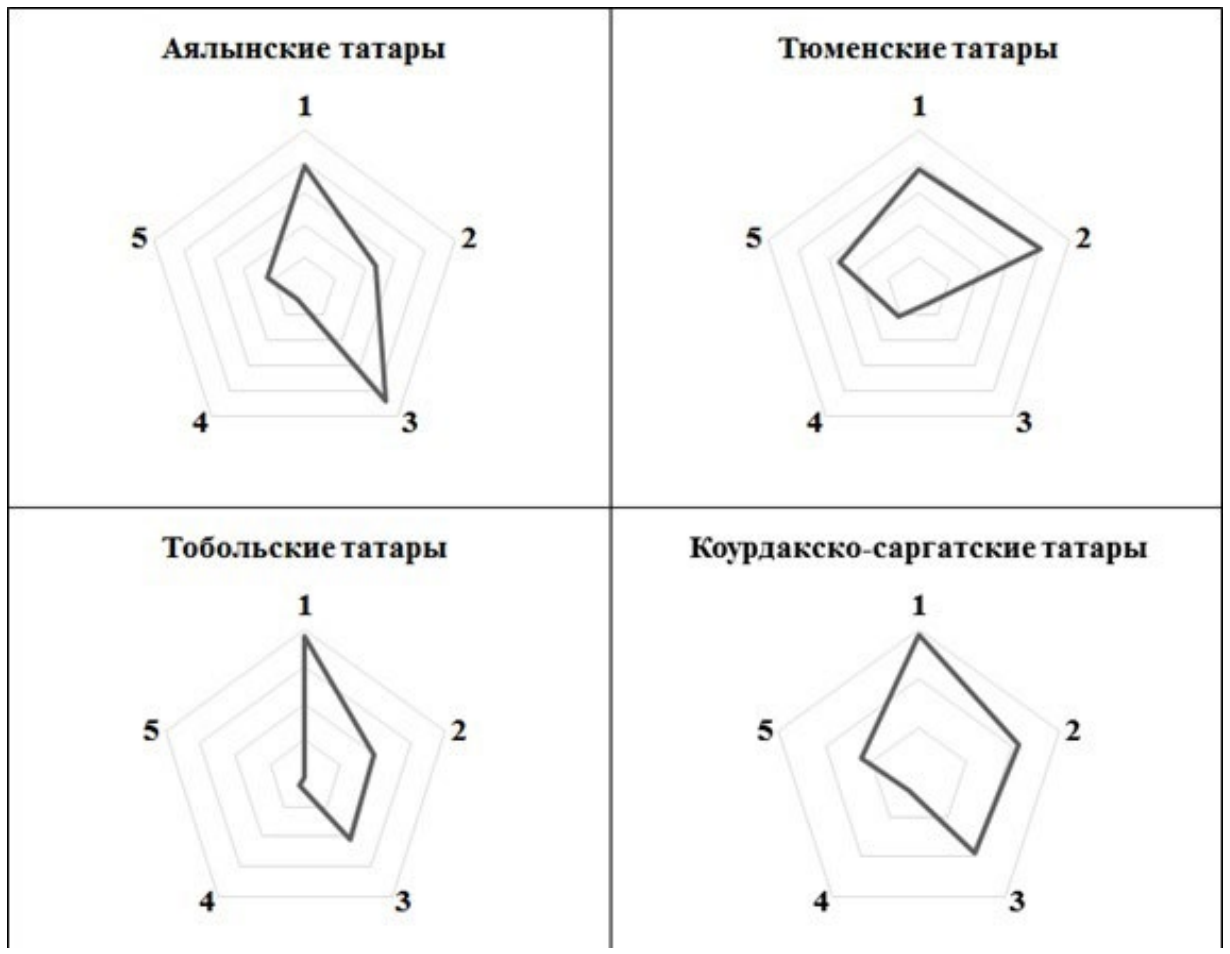

Рис. 2. Комбинационные полигоны общей асимметричности класса кости (женщины):

1 - плечевая кость; 2 -лучевая кость; 3 -локтевая кость; 4-бедренная кость; 5 - большая берияовая кость.

Выявленные различия в асимметрии длинных костей скелета в группах тоболо-иртышских татар, вероятно, могут быть связаны с их хозяйственным укладом жизни. Ведь как известно группы, обитающие в определённых естественно-географических условиях имеют различные комплексы особенностей хозяйства и культуры, или другими словами, обладают особым хозяйственно-культурным типом (Левин, Чебоксаров 1955). К примеру, Тоболо-иртышское междуречье (территория проживания тюменских и тобольских татар) изобиловало протоками, озерами и болотами, что делало почти невозможным нормальное ведение земледельческого хозяйства. В хозяйстве же коренного населения Тарского Прииртышья (ареал аялынских татар) существенная роль принадлежала рыболовству, а охота на пушных зверей была распространена главным образом у татар, живущих в таежной полосе (коурдакско-саргатская группа). Тут татары промышляли белку, соболя, медведя и других животных, поскольку охота доставляла основной продукт питания и удовлетворяла потребности в одежде (Бояршинова 1960; История Сибири, 1968; Томилов 1981; Халиков 2002).

Таким образом, адаптивные возможности популяций к определенным условиям существования в различных физико-географических условиях могли влиять на изменения скелетной системы человека, которые проявлялись в наличии билатеральной асимметрии.

\section{Заключение}

Полученные данные по коэффициентам асимметрии тоболо-иртышских татар ещё раз подтверждают наличие у человека хорошо выраженной правосторонней асимме- 
трии руки, и перекрёстной у обеих конечностей: правая рука - левая нога. Поэтому тезис В.Г. Властовского о том, что стоит различать морфологическую и функциональную асимметрию остаётся актуальным. И при интерпретации данных и выделении, к примеру, функциональной асимметрии, которая является следствием использования преимущественно правой руки, нужно подходить с осторожностью (Властовский 1960).

Как известно физико-географические условия и особенности ландшафта территории расселения тех или иных этно-территориальных групп на первый план выводят определенные виды хозяйствования. Поэтому в данном случае можно предположить, что преобладание того или иного типа ведения хозяйства в группах тоболо-иртышских татар отразилось на формировании скелетной системы человека, что и подтверждается наличием билатеральной асимметрии.

Дальнейшее накопление данных по коэффициентам асимметрии палеопопуляций и работа в этом направлении, а также серьезное внимание к проблемам теоретического осмысления использования показателей асимметрии поможет прояснить сложную проблему асимметрии билатеральных структур в палеопопуляциях.

\section{Научная литература}

$A н$ C.B. Межгрупповая изменчивость индексов асимметрии лицевого отдела черепа человека. Морфология, 1999. Т. 104. Вып. 1-2. С. 112-123.

Ан С.В. Асимметрия лицевого отдела черепа человека. Морфологический анализ. Дисс. канд. биол. наук. Москва, 1993.

Багашёв А.Н. Антропологический состав и формирование тоболо-иртышских татар по данным краниоостеологии. Дисс. канд. ист. наук. Москва, 1989.

Багашёв А.Н. Этническая антропология тоболо-иртышских татар. Новосибирск: Наука, 1993.

Березина Н.Я. Анализ показателей билатеральной асимметрии длинных костей конечностей раннесредневекового населения Северной Осетии (по материалам могильника Мамисондон. Вестник Московского университета. Серия 23: Антропология, 2017. № 3. С. 104-113.

Бояриинова 3.Я. Население Западной Сибири до начала русской колонизации (Виды хоз. деятельности и общественный строй местного населения). Томск: Изд-во Том. ун-та, 1960.

Брагина Н.Н., Доброхотова Т.А. Функииональные асимметрии человека. 2-е изд. Москва: Медицина, 1981.

Бужилова А.П., Карасева Н.М. Асимметрия зубов в группах коренного населения арктического пояса (по материалам краниологических коллекций МГУ). Вестник Московского университета. Серия 23: Антропология, 2017. № 4. С. 119-132.

Властовский В.Г. Об асимметрии скелета конечностей человека. Вопросы антропологии, 1960. Вып. 3. С. 3-11.

Гинзбург В.В. Об асимметрии конечностей человека. Природа, 1947. №8. С. 42-46.

Дубовик Е.И. Асимметрия лицевого черепа при различных его формах у взрослого человека. Дисс. канд. мед. наук. Санкт-Петербург, 2009.

Зорина A.A. Методы статистического анализа флуктуирующей асимметрии. Принципьл экологии, 2012. № 3. С. 24-47.

Зорина А.А. Формирование флуктуирующей асимметрии в процессе индивидуального развития Betula pendula. Принципь экологии, 2014. № 4. С. 31-52.

Зубов А.А., Халдеева Н.И. Одонтология в современной антропологии. Москва: Наука, 1989.

Корусенко М.А. Отчет об археологических раскопках курганно-грунтового могильника Чеплярово 27 в 2009 г. Архив МНС ОФ ИАЭТ СО РАН. Ф. VІІ-1. Д. 5-1. Омск, 2010.

Левин М.Г., Чебоксаров Н.Н. Хозяйственно-культурные типы и историко-этнографические области (к постановке проблемы) // Советская этнография, 1955. № 4. С.3-17. 
Николаева Е.Ю. Влияние асимметрии лицевого скелета на степень тяжести аномалий зубочелюстной системы и её ортодонтическая коррекция. Автореф. дисс. канд. мед. наук. Тверь, 2007.

История Сибири с древнейших времён до наших дней. В пяти томах. Том первый. Древняя Сибирь. Окладников А.П. (гл. ред.). Ленинград: Наука. Ленингр. отделение, 1968.

Пежемский Д.В. Остеологическая характеристика калаусских ногайцев (морфология длинных костей скелета) // Материаль по изучению историко-культурного наследия Северного Кавказа. Bbin. IV. Москва: Памятники исторической мысли, 2003. С. 83-92.

Рождественский К.Г. Некоторые данные к вопросу об асимметрии скелета конечностей человека. Известия Северо-Кавказского университета. Медиџина и естествознание, 1929. T. 1. (XVII). C. 113-140.

Томилов Н.А. Тюркоязычное население Западно-Сибирской равнины в коние XVI- первой четверти ХІХ вв. Томск: Изд-во Томск. ун-та, 1981.

Typ C.C. Билатеральная асимметрия длинных костей конечностей у скотоводов Алтая эпохи бронзы и раннего железного века. Археология, этнография и антропология Евразии, 2014. № 3 (59). C. 141-156.

Халиков Н.А. Этнокультурные особенности хозяйства западносибирских татар // Сибирские maтары. Монография. Казань: Институт истории АН РТ, 2002. С. 59-85.

Худавердян А.Ю. Флуктуирующая асимметрия зубной системы у древнего населения Армении. Вестник Новосибирского государственного университета, 2014. Т. 13. Вып. 3. С. 226-233. Leigh Van Valen. A Study of Fluctuating Asymmetry. Evolution, 1962. Vol. 16. № 2. P. 125-142. Palmer A.R. Fluctuating asymmetry analyses: A primer // Developmental Instability: Its Origins and Evolutionary Implications / T. Markow, Ed. Dordrecht, The Netherlands: Kluwer, 1994. P. 335-364.

Dedik Alyona $V$.

\section{Limb bone bilateral asymmetry among the Tobol-Irtysh Tatars}

DOI: $10.33876 / 2311-0546 / 2021-54-2 / 292-310$

The article presents the results of studying the limb bone bilateral asymmetry in four groups of the Tobol-Irtysh Tatars: Ayalyn, Tobolsk, Tyumen and Kourdak-Sargat Tatars. The asymmetry coefficients were calculated for the male and female samples of each group (using the $R-L$ formula). The Ayalyn Tatars resulted to have the most symmetric skeletal system, while the Kourdak-Sargat Tatars - the least symmetrical one. The analysis of the asymmetry coefficients of individual bones revealed that the humerus is the most asymmetric bone in both sexes among all the studied groups. The lengths of the upper limb bones resulted to be the most asymmetrical measurement in all groups. Left-sided asymmetry was mainly seen in the lower limb bones among the Tobol-Irtysh Tatars. No sex differences in the asymmetry coefficients were revealed. Combination polygons were produced to illustrate the variability of the asymmetry coefficients for the male and female samples. Male samples of the Tobolsk and Kourdak-Sargat Tatars were found to be most similar to each other, and the Ayalyn and Tyumen Tatars are noticeably different both from these groups and from each other. The combination polygons of the female samples of the Tobol-Irtysh Tatars do not reveal any visible similarity between them. Thus, the revealed differences in the asymmetry of the skeletal system of the Tobol-Irtysh Tatars ethno-territorial groups are possibly associated with different economy systems of the groups.

Keywords: physical anthropology, bilateral asymmetry, the Tobol-Irtysh Tatars.

For citation: Dedik, Alyona V. 2021. Limb bone bilateral asymmetry among the TobolIrtysh Tatars. Herald of Anthropology (Vestnik Antropologii) 2: 292-310. 


\section{Author Info:}

Dedik, Alyona Vladimirovna - Laboratory of Archeology, Ethnography and History of Siberia, Humanitarian Institute, Siberian Federal University, Krasnoyarsk, Russia (Krasnoyarsk, Svobodny Ave., 82 A). E-mail: ejara.ru@mail.ru.

Funding: The article is an expanded version of the report presented at the V Youth Anthropological Conference "Actual Problems of Physical Anthropology: Continuity and New Approaches", March 25-28, 2019 in Moscow.

\section{References}

An, S.V. 1999. Mezhgruppovaya izmenchivost' indeksov asimmetrii litsevogo otdela cherepa cheloveka [Intergroup variability of the asymmetry indices of the facial part of the human skull]. Morfologiya 104 (1-2): 112-123.

An, S.V. 1993. Asimmetriya litsevogo otdela cherepa cheloveka. Morfologicheskiy analiz [Asymmetry of the facial section of the human skull. Morphological analysis]. PhD diss., Moscow Medical Dental Institute.

Bagashev, A.N. 1989. Antropologicheskiy sostav i formirovanie tobolo-irtyshskikh tatar po dannym kranioosteologii [Anthropological composition and formation of the Tobol-Irtysh Tatars according to cranio-osteology data]. PhD diss., Tomsk state university.

Bagashev, A.N. 1993. Etnicheskaya antropologiya tobolo-irtyshskikh tatar [Ethnic anthropology of the Tobol-Irtysh Tatars]. Novosibirsk: Nauka.

Berezina, N.Ya. 2017. Analiz pokazateley bilateral'noy asimmetrii dlinnykh kostey konechnostey rannesrednevekovogo naseleniya Severnoy Osetii (po materialam mogil'nika Mamisondon [Analysis of indicators of bilateral asymmetry of the long bones of the extremities of the early medieval population of North Ossetia (based on materials from the Mamisondon burial ground]. Vestnik Moskovskogo universiteta 23, 3: 104-113.

Boiarshinova, Z.Ya. 1960. Naselenie Zapadnoy Sibiri do nachala russkoy kolonizatsii (Vidy khozyastvennoy deiatel'nosti i obshchestvennyy stroy mestnogo naseleniya) [The population of Western Siberia before the beginning of Russian colonization (Types of economic activities and social structure of the local population)]. Tomsk: Izdatel'stvo Tomsk University.

Bragina, N.N., and T.A. Dobrokhotova, 1981. Funktsional'nye asimmetrii cheloveka. 2-e izd [Human functional asymmetries. The second edition]. Moscow: Meditsina.

Buzhilova, A.P., and N.M. Karaseva, 2017. Asimmetriya zubov v gruppakh korennogo naseleniya arkticheskogo poyasa (po materialam kraniologicheskikh kollektsiy Moscovskogo gosudarstvennogo universiteta) [Teeth asymmetry in indigenous groups of the Arctic zone (based on materials from the craniological collections of Moscow State University)]. Vestnik Moskovskogo universiteta 23 (4): 119-132.

Vlastovskiy, V.G. 1960. Ob asimmetrii skeleta konechnostey cheloveka [On the asymmetry of the skeleton of human limbs]. Voprosy antropologii 3: 3-11.

Ginzburg, V.V. 1947. Ob asimmetrii konechnostey cheloveka [On the asymmetry of human limbs]. Priroda 8: 42-46.

Dubovik, E.I. 2009. Asimmetriya litsevogo cherepa pri razlichnykh ego formakh u vzroslogo cheloveka [Asymmetry of the facial skull in its various forms in an adult]. PhD diss., Military-medical Academy.

Zorina, A.A. 2012. Metody statisticheskogo analiza fluktuiruiushchei asimmetrii [Methods for statistical analysis of fluctuating asymmetry]. Printsipy ekologii 3: 24-47.

Zorina, A.A. 2014. Formirovanie fluktuiruiushchei asimmetrii v protsesse individual'nogo razvitiia Vetula pendula [Formation of fluctuating asymmetry in the process of individual development of Betula pendula]. Printsipy ekologii 4: 31-52. 
Zubov, A.A., and N.I. Khaldeeva. 1989. Odontologiya v sovremennoy antropologii [Odontology in modern anthropology]. Moscow: Nauka.

Levin, M.G., and N.N. CHeboksarov. 1955. Hozyajstvenno-kul'turnye tipy i istoriko-etnograficheskie oblasti (k postanovke problemy) [Economic and cultural types and historical and ethnographic areas (to the statement of the problem)]. Sovetskaya etnografiya 4: 3-17.

Korusenko, M.A. 2010. Otchet ob arkheologicheskikh raskopkakh kurganno-gruntovogo mogil'nika Cheplyarovo 27 v $2009 \mathrm{~g}$. [Report on the archaeological excavations of the Cheplyarovo 27 burial ground in 2009]. Arkhiv MNS OF IAET SO RAN. F. VII-1. D. 5-1. Omsk.

Nikolaeva, E.Yu. 2007. Vliyanie asimmetrii litsevogo skeleta na stepen' tyazhesti anomalii zubocheliustnoy sistemy $i$ eyo ortodonticheskaya korrektsiya [Influence of asymmetry of the facial skeleton on the severity of anomalies of the dentoalveolar system and its orthodontic correction]. PhD diss. abstract, Nizhny Novgorod State Medical Academy.

Okladnikov, A.P. (ed.). Istoriya Sibiri s drevneishikh vremen do nashikh dnei. V pyati tomakh. 1968. [History of Siberia from ancient times to the present day. In five volumes.]. Vol. 1. Drevnyaya Sibir'[Ancient Siberia]. Leningrad: Nauka. Leningradskoe otdelenie.

Pezhemskiy, D.V. 2003. Osteologicheskaya kharakteristika kalausskikh nogaitsev (morfologiya dlinnykh kostey skeleta) [Osteological characteristics of the Kalaus Nogai (morphology of the long bones of the skeleton)]. Materialy po izucheniiu istoriko-kul'turnogo naslediia Severnogo Kavkaza. Vol. IV: 83-92. Moscow: Pamiatniki istoricheskoi mysli.

Rozhdestvenskiy, K.G. 1929. Nekotorye dannye k voprosu ob asimmetrii skeleta konechnostey cheloveka [Some data on the question of the asymmetry of the skeleton of human limbs]. Izvestiya Severo-Kavkazskogo universiteta. Meditsina i estestvoznanie 1 (17): 113-140.

Tomilov, N.A. 1981. Tiurkoyazychnoe naselenie Zapadno-Sibirskoy ravniny v kontse XVI-pervoy chetverti XIX vv. [The Turkic-speaking population of the West Siberian Plain at the end of the $16^{\text {th }}-$ first quarter of the $19^{\text {th }}$ centuries.]. Tomsk: Izdatel'stvo Tomsk University.

Tur, S.S. 2014. Bilateral'naya asimmetriya dlinnykh kostei konechnostey u skotovodov Altaya epokhi bronzy i rannego zheleznogo veka [Bilateral asymmetry of the long bones of the limbs in Altai cattle breeders of the Bronze Age and the Early Iron Age]. Arkheologiya, etnografiya $i$ antropologiya Evrazii 3 (59): 141-156.

Khalikov, N.A. 2002. Etnokul'turnye osobennosti khoziaystva zapadnosibirskikh tatar [Ethnocultural features of the economy of the West Siberian Tatars]. Sibirskie tatary. Monografiya, 59-85. Kazan': Institut istorii AN RT.

Khudaverdian, A.Yu. 2014. Fluktuiruiushchaya asimmetriya zubnoy sistemy u drevnego naseleniya Armenii [Fluctuating asymmetry of the dental system in the ancient population of Armenia]. Vestnik Novosibirskogo gosudarstvennogo universiteta 13 (3): 226-233.

Van Valen, Leigh. 1962. A Study of Fluctuating Asymmetry. Evolution 16 (2): 125-142.

Palmer, A.R. 1994. Fluctuating asymmetry analyses: A primer. In Developmental Instability: Its Origins and Evolutionary Implicatio, edited by T. Markow, 335-364. Dordrecht, The Netherlands: Kluwer. 